\title{
PENGARUH PENGGUNAAN ENERGI TERBARUKAN BUTANOL TERHADAP PENURUNAN EMISI JELAGA MESIN DIESEL INJEKSI LANGSUNG BERBAHAN BAKAR BIODIESEL CAMPURAN SOLAR DAN JATROPA
}

\author{
Syarifudin $^{1}$, Syaiful $^{2}$ \\ ${ }^{1}$ Program Studi Teknik Mesin, Politeknik Harapan Bersama \\ ${ }^{2}$ Program Studi Magister Teknik Mesin, Universitas Diponegoro \\ masudinsyarif88@gmail.com ${ }^{1}$, syaiful.undip2011@gmail.com ${ }^{2}$
}

\begin{tabular}{ll}
\hline & Abstrak \\
\hline Kata Kunci: & \\
EGR; & Mesin diesel banyak digunakan sebagai tenaga penggerak pada kendaraan dan industri \\
butanol; & karena efisiensi bahan bakar dan daya output yang tinggi. Luasnya penggunaan mesin \\
jatropa; & diesel memicu peningkatan konsumsi bahan bakar dan emisi gas buang yang \\
jelaga; & berbahaya bagi kesehatan. Jatropa merupakan bahan bakar terbarukan sebagai solusi \\
solar. & peningkatan konsumsi bahan bakar. Namun, tingginya viskositas dan rendahnya nilai \\
& kalor mengakibatkan penurunan performa dan peningkatan emisi gas buang. Butanol \\
& memiliki kandungan oksigen dan angka setana yang tinggi serta viskositas yang rendah \\
& dibandingkan solar dan jatropa. Penambahan butanol dimungkinkan dapat mengurangi \\
& penurunan performa dan emisi gas buang mesin diesel. penelitian ini mengevaluasi \\
& pengaruh butanol terhadap penurunan emisi jelaga mesin diesel injeksi langsung Isuzu \\
& 4JB1. Persentase campuran yang dipakai 70/30/0, 65/30/5, 60/30/10, dan 55/40/15 \\
& berbasis volume. Pengujian dilakukan pada putaran konstant 2500 dengan pembebanan \\
& 25\% sampai $100 \%$ menggunakan sistem EGR. Hasil eksperimen menunjukkan adanya \\
& butanol menyebabkan penurunan emisi jelaga yang dihasilkan mesin diesel.
\end{tabular}

\begin{tabular}{|c|c|}
\hline & Abstract \\
\hline $\begin{array}{l}\text { Keywords: } \\
\text { EGR; } \\
\text { butanol; } \\
\text { jatropa; } \\
\text { soot; } \\
\text { diesel. }\end{array}$ & $\begin{array}{l}\text { Diesel engines are widely used as driving forces in vehicles and industry due to fuel } \\
\text { efficiency and high output power. The wide use of diesel engines triggers an increase } \\
\text { in fuel consumption and exhaust emissions that are harmful to health. Jatropha is a } \\
\text { renewable fuel as a solution to increase fuel consumption. However, the high viscosity } \\
\text { and low calorific value result in reduced performance and increased exhaust emissions. } \\
\text { Butanol has not only a high oxygen content and cetane number but also low viscosity } \\
\text { compared to diesel and jatropha. Addition of butanol makes it possible to reduce the } \\
\text { decrease in performance and exhaust emissions of diesel engines. This study evaluates } \\
\text { the effect of butanol in reducing Isuzu } 4 \mathrm{JB} 1 \text { diesel engine direct injection emissions. } \\
\text { The blending percentage used is } 70 / 30 / 0,65 / 30 / 5 \text {, } 60 / 30 / 10 \text {, and } 55 / 40 / 15 \text { based on } \\
\text { volume. Tests are carried out at } 2500 \text { constant turns with a loading of } 25 \% \text { to } 100 \% \\
\text { using the EGR system. The experimental results showed that the presence of butanol } \\
\text { caused a decrease in soot emissions produced by diesel engines }\end{array}$ \\
\hline
\end{tabular}

\footnotetext{
Alamat korespondensi:

E-mail: masudinsyarif88@gmail.com

ISSN : 2087-1627
} 


\section{Pendahuluan}

Mesin diesel secara luas digunakan karena efisiensi bahan bakar dan daya yang tinggi dibandingkan mesin bensin. Hal ini menjadikan mesin diesel banyak digunakan sebagai tenaga penggerak pada kendaraan berat maupun alat angkut pada dunia industri maupun industri otomotif [1] Kelebihan yang lain dari mesin diesel adalah fleksibelitas jenis bahan bakar yang bisa digunakan seperti solar, jatropa, dan energi terbarukan butanol, metanol, etanol dsb. Hal ini dikarenakan pembakaran yang terjadi tidak memerlukan pengontrolan bunga api[2].

Bahan bakar solar memiliki struktur kimia yang terdiri dari atom dan hidrogen dengan struktur rantai yang lurus. Struktur ini sangat cocok karena kualitas pengapian yang lebih baik sehingga mendukung proses pembakaran yang sempurna [3]. Akan tetapi, luasnya penggunaan mesin diesel menyebabkan peningkatan konsumsi bahan bakar dan emisi gas buang [4].

Jatropa adalah bahan bakar alternative yang dapat dijadikan sebagai pengganti bahan bakar solar. Jatropa diproduksi dari tanaman yang tidak dikonsumsi manusia/tidak dimakan. Penggunaan jatropa sebagai bahan bakar tidak mengurangi daya output mesin diesel. Penambahan jatropa $20 \%$ menghasilkan performa dan konsumsi bahan bakar yang hampir sama dengan bahan bakar solar murni [5]. Akan tetapi, penggunaan jatropa masih menghasilkan emisi asap (smoke) yang lebih tinggi dibandingkan solar murni. Ketebalan emisi asap yang keluar dapat dilihat dari indikator persentase Pratikulat Matter atau smoke opacity. Ketebalan emisi asap menurun ketika dicampur dengan alkohol sebesar $30 \%$ (berbasis volume) meskipun nilainya masih lebih tinggi dibandingkan solar murni ${ }^{[6]}$.

Menurut Fayad dkk., (2017) [7], bahwa penurunan emisi asap (soot) mesin diesel dipengaruhi viskositas yang rendah dan kadar oksigen yang tinggi dalam alkohol butanol. Hal ini terlihat dari berkurangnya dimensi partikulat matter (PM) pada jelaga. Tendensi penurunan emisi jelaga (soot) juga terjadi pada penelitian Huang dkk., (2017) [8]. Kandungan oksigen yang tinggi dalam butanol menghasilkan emisi jelaga yang lebih rendah dibandingkan bahan bakar campuran diesel dan biodiesel. Akan tetapi, semakin tinggi kandungan alkohol akan meningkatkan emisi Nox [9].

Exhaust Gas Recirculating (EGR) adalah teknik mensirkulasikan kembali sebagian gas buang ke dalam ruang bakar. Teknik ini terbukti efektif dan murah untuk menurunkan emisi NOx. Gas buang yang didinginkan terlebih dahulu (tipe cold EGR) sebelum masuk ke dalam ruang bakar, dinilai paling efektif dalam mengurangi emisi NOx. Peningkatan persentase EGR akan menaikkan emisi jelaga (soot) [10],[11].
Berdasarkan hal tersebut diatas, penelitian ini mengobservasi tentang pengaruh penggunaan butanol untuk menurunkan emisi jelaga (soot) yang dihasilkan pada mesin diesel injeksi langsung dengan sistem cold EGR. Bahan bakar yang digunakan adalah bahan bakar campuran diesel dan jatropa dengan penambahan butanol sebesar 5\%, $10 \%$ dan $15 \%$ berbasis volume.

\section{Metode Penelitian}

Pengujian dilaksanakan di Laboratorium Thermofluida Universitas Diponegoro tahun 2018. Eksperimen dilakukan dengan sebuah mesin diesel injeksi langsung 4 silinder tipe Isuzu 4JB1 yang spesifikasinya dijelaskan pada tabel 1 . Pengujian dilakukan pada putaran stasioner $2500 \mathrm{rpm}$. Pembukaan katup EGR divariasikan yaitu 0 dan $100 \%$. Masing-masing campuran diberi beban dari $25 \%$ sampai $100 \%$ dengan interval pembebanan $25 \%$. Adapun karakteristik bahan bakar diesel, jatropa dan butanol dipaparkan pada tabel 1 .

Bahan bakar diesel diperoleh dari SPBU Pertamina, sedangkan jatropa dan butanol diperoleh dari supplier komersial di Semarang. Karakteristik utama masing-masing bahan bakar tersebut ditunjukkan pada tabel 2. Persentase volume minyak jarak sebesar $30 \%$. Sedangkan persentase volume butanol yang diuji adalah 0\%, 5\%, 10\%, dan $15 \%$ dari volume diesel. Secara berurutan disebut DJ30, DJ30B5, DJ30B10, dan DJ30B15. Sebelum pengujian, bahan bakar diaduk menggunakan mixer agar menjadi homogen.

Tabel 1. Spesifikasi mesin diesel

\begin{tabular}{|l|l|}
\hline \multicolumn{1}{|c|}{ Keterangan } & \multicolumn{1}{|c|}{ Spesifikasi / Nilai } \\
\hline $\begin{array}{l}\text { Model of engine } \\
\text { type }\end{array}$ & $\begin{array}{l}\text { Isuzu 4JB1 } \\
4 \text { cylinder, 4 cycle, OHV, } \\
\text { vertical in-line direct } \\
\text { injection }\end{array}$ \\
\hline Cylinder number & 4 \\
\hline Cylinder bore & $93 \mathrm{~mm}$ \\
\hline Cylinder stroke & $102 \mathrm{~mm}$ \\
\hline $\begin{array}{l}\text { Compression } \\
\text { ratio }\end{array}$ & $18,2: 1$ \\
\hline $\begin{array}{l}\text { Compression } \\
\text { pressure }\end{array}$ & $31 \mathrm{~kg} / \mathrm{cm}^{2}$ \\
\hline $\begin{array}{l}\text { Total cylinder } \\
\text { volume }\end{array}$ & $2771 \mathrm{cc}$ \\
\hline Maximum power & $52.2 \mathrm{~kW}$ at $3000 \mathrm{rpm}$ \\
\hline Maximum torque & $178,96 \mathrm{Nm}$ at $2000 \mathrm{rpm}$ \\
\hline
\end{tabular}


Pda Gambar 3 menunjukan pengaruh butanol terhadap emisi jelaga mesin diesel injeksi langsung 4JB1 dengan sistem EGR. Secara umum, penggunaan bahan bakar campuran diesel-jatropabutanol menghasilkan penurunan smoke opacity dibandingkan tanpa butanol. Penurunan tertinggi terjadi pada penggunaan bahan bakar campuran diesel dan jatropa dengan konsentrasi butanol sebesar $15 \%$ saat pembebanan rendah. Pengujian smoke opacity ini nilainya lebih tinggi dibandingkan pengujian tanpa sistem EGR. Berkurangnya konsentrasi oksigen akibat kehadiran gas $\mathrm{CO} 2$ di dalam ruang bakar mengakibatkan pembakaran yang tidak sempurna sehingga memicu penurunan temperatur ruang bakar dan peningkatan nilai smoke opacity[10].

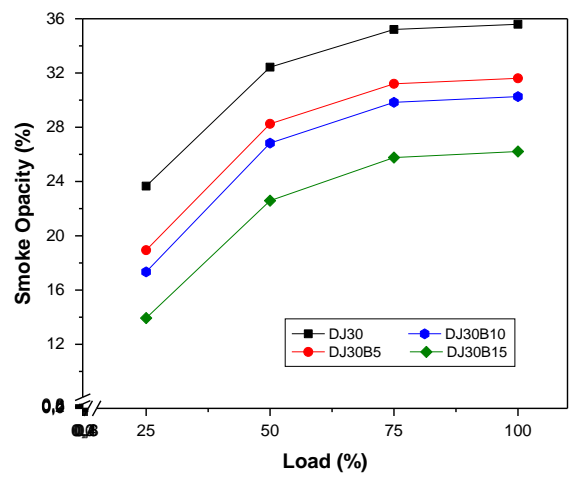

Gambar 3. Pengaruh butanol terhadap smoke opacity dengan sistem EGR

\section{Kesimpulan}

Penggunaan bahan bakar campuran solarjatropa-butanol tanpa sistem EGR menghasilkan penurunan emisi jelaga dibandingkan tanpa butanol. Semakin tinggi kandungan butanol semakin tinggi penurunan emisi jelaga. Rendahnya viskositas dalam butanol merupakan faktor utama penurunan emisi jelaga. Penggunaan bahan bakar campuran solar-jatropa-butanol dengan sistem EGR juga menghasilkan penurunan emisi jelaga dibandingkan tanpa butanol meskipun nilainya lebih tinggi dibandingkan tanpa sistem EGR. Berkurangnya konsentrasi okisgen akibat suplai udara luar (cold EGR) merupakan faktor penyebab nilainya lebih tinggi dibandingkan tanpa EGR. Bahan bakar campuran solar dan jatropa dengan kandungan butanol $15 \%$ adalah bahan bakar yang menghasilkan penurunan emisi jelaga tertinggi.

\section{Daftar Pustaka}

[1] Yie Hua Tan, Mohammad Omar Abdullah, Cirilo Nolasco, Nur Syuhada Ahmad Fauzi, Georgie Wong Abdullah, 2017. "Engine Performance and Emissions Characteristic of a Diesel Engine Fueled With Dieselbiodiesel-bioethanol Emulsions". Elsevier, Energy Conversion and Management, 132, pp. 54-64.

[2] Sugeng dan Syaiful, 2013. "Efek Metanol Kadar Rendah terhadap Efisiensi Termal Mesin Diesel Injeksi Langsung dengan Sistem EGR". Proseding SNST ke-4. Fakultas Teknik Universitas Wahid Hasyim Semarang.

[3] A. Amin, A. GadallaH, A.K. El Morsi, N.N. El-Ibiari, G.I. El-Diwani, 2015. "Experimental and empirical study of diesel and castor biodiesel blending effect, on kinematic viscosity, density and calorific value", Egyptian Journal of Petroleum.

[4] Kurnia Uwais Alqorni Purwatama dan Syaiful, 2014. "Performa dan Emisi Jelaga dari Mesin Diesel pada Putaran Rendah dengan menggunakan Bahan Bakar Campuran Biosolar dan Metanol Kadar Rendah". JTM (S-1). Universitas Diponegoro, Vol. 2, No.1.

[5] Eka Darmana, Syaiful, dan Berkah Fajar, 2013. "Pengaruh Cold EGR terhadap Brake Power pada Mesin Diesel dengan Bahan Bakar Campuran Solar dan Jatropa". Eksergi Jurnal Teknik Energi. Politeknik Negeri Semarang, Vol. 9, No. 3.

[6] M., Senthilkumar, R., Ramados, K., Manimaran, R, 2003. "Experimental Investigation of Performance and Emission Characteristic by Different Exhaust Gas Recirculation Methods used in Diesel Engine", Global Journal of Researches In Engineering Mechanical and Mechanics Engineering, 13, Issue 1.

[7] M. A. Fayad, A. Tsolakis, D. FernándezRodríguez, J.M. Herreros, F.J. Martos, M. Lapuerta, 2017. "Manipulating Modern Diesel Engine Particulate Emission Characteristics Through Butanol Fuel Blending and Fuel Injection Strategies for Efficient Diesel Oxidation Catalysts". Elsevier. Applied Energy, 190, pp. 490-500.

[8] Huang Haozhong Qingsheng Liu, Wenwen Teng, Qingxin Wang, 2017. "The Potentials for Improving Combustion Performance and Emissions in Diesel Engines by Fueling $N$ butanol/Diesel/PODE Blends" Energy Procedia, 105, pp. 914-920.

[9] Sayin, C., 2010. "Engine Performance and Exhaust Gas Emission of Methanol and Ethanol-Diesel Blends", Fuel, 89, pp. 34103415.

[10] Pradeep, V., and Sharma, R.P., 2007. "Use Hot EGR for Nox Control in a Compression Ignition Engine Fuelled with Bio-Diesel from Jatropha Oil', Renewable Energy, 32, pp.1136-1154. 
[11] Donghui Qi, Michael Leick, Yu Liu, Chiafon F. Lee, 2011. "Effect of EGR and injection timing on combustion and emission characteristics of split injection strategy DIdiesel engine fueled with biodiesel". Fuel 90, pp. 1884-1891.
[12] Xue, Jinlin., Grift, Tony., Hansen, A., 2011. "Effect of Biodiesel on Engine Performance and Emissions", Renewable And Sustainable Energy Reviews, 91, pp. 1761-1767. 